\title{
COMPARAÇÃO ENTRE O ÍNDICE TOPOGRÁFICO E O TASSELED CAP WETNESS NA ESTIMATIVA DA UMIDADE DO SOLO NA BACIA HIDROGRÁFICA DO RIO CORREDEIRAS - SC
}

\author{
Marcelo Ng Wei Ban Hung ${ }^{(a)}$, Fernando Helmuth Syring Marangon ${ }^{(b)}$ Irani dos Santos ${ }^{(c),}$
}

(a) Departamento de Geografia, Universidade Federal do Paraná, marcelo.hung1@ gamil.com

(b) Departamento de Geografia ,Universidade Federal do Paraná, fhsmarangon@ gmail.com

(c) Departamento de Geografia ,Universidade Federal do Paraná, irani69@gmail.com

\section{EIXO: BACIAS HIDROGRÁFICAS E RECURSOS HÍDRICOS: ANÁLISE, PLANEJAMENTO E GESTÃO}

\begin{abstract}
Resumo
O índice topográfico (IT) é um atributo espacial que representa a propensão à saturação hídrica do solo de determinadas áreas de uma bacia hidrográfica. Além disso, utilizando o sensoriamento remoto torna-se possível analisar a variabilidade espaço-temporal da umidade na paisagem, no qual o índice Tasseled Cap Wetness (TCW) se destaca. O objetivo do trabalho foi comparar o IT e o TCW na estimativa do teor água do solo na bacia do rio Corredeiras - SC. O IT representou a distribuição espacial das áreas com maior probabilidade de saturação de forma mais próxima da realidade, principalmente nas porções mais próximas da rede de drenagem e de sua planície fluvial. Por outro lado, o TCW apresentou limitações devido a influência da vegetação extremamente densa que impossibilitou o índice em detectar a umidade presente no solo, apresentando em sua grande maioria, áreas com maior cobertura vegetal como as zonas mais úmidas.
\end{abstract}

Palavras chave: Umidade do Solo, Índice Topográfico, Tasseled Cap Wetness.

\section{Introdução}

As áreas úmidas são ecossistemas frágeis, de alta complexidade ecológica e são fundamentais para a estabilidade ambiental e a manutenção da biodiversidade, sendo que geralmente localizam-se em relevos planos com elevados níveis de saturação hídrica do solo por períodos prolongados. Essa situação gera uma maior capacidade de fixação do carbono no solo, além de colaborar na regularização da vazão dos rios. Conforme a Lei Florestal Brasileira, as áreas úmidas correspondem às superfícies cobertas periodicamente por água, com a presença original de florestas ou vegetação adaptadas à inundação (BRASIL, 2012). Deste modo, as funções ecológicas das áreas úmidas são fundamentais no que se refere à regulação dos regimes hídricos, biodiversidade e habitat da fauna e flora, e constituem-se como recursos de grande valor econômico, cultural, científico e recreativo, cuja perda seria irreparável (PARANÁ, 2008). 
XVII Simpósio Brasileiro

de Geografia Fisica Aplicada

I Congresso Nacional

de Geografia Física
OS DESAFIOS DA GEOGRAFIA FÍSICA NA FRONTEIRA DO CONHECIMENTO

Instituto de Geociências - Unicamp

Campinas - SP

28 de Junho à 02 de Julho de 2017

As características topográficas do relevo possuem grande influência sobre a dinâmica da água, sendo que em relevos mais acidentados com declividades mais acentuadas e solos mais rasos, geralmente a água é armazenada em menor quantidade sendo rapidamente escoada para as áreas mais baixas. $\mathrm{O}$ contrário ocorre em casos de relevo com declividades mais suaves e áreas mais planas, no qual possuem maior capacidade de armazenar a água da chuva, contribuindo para a manutenção de uma vazão mínima mais elevada dos rios (DUNNE, 1978; HEWLETT e HIBBERT, 1967).

Neste contexto, uma variável que demonstra a propensão à saturação hídrica do solo em uma bacia hidrográfica é o índice topográfico (IT). Este índice utiliza a declividade do terreno e a área de contribuição para indicar as áreas de maior umidade potencial dentro da bacia hidrográfica, isto é, este índice sistematiza o conceito de similaridade hidrológica determinando que áreas com o mesmo valor do índice apresentam comportamento hidrológico semelhante (SILVA, 2012). Desta forma, quanto maior for o valor do IT, maior será a tendência do local à saturação hídrica, ou seja, são regiões de escoamento superficial com grande área de contribuição, baixa declividade e relevos mais planos. Já os menores valores do índice são encontrados normalmente nos terços superiores das vertentes onde a área de contribuição é pequena, a declividade é alta e os solos são mais rasos, sendo normalmente áreas de recarga de água subterrânea (FREER et al., 2002).

Por outro lado, nas últimas décadas as técnicas de sensoriamento remoto têm sido de fundamental importância no monitoramento e mapeamento dos recursos naturais. Utilizando imagens de satélite e o geoprocessamento, é possível fazer análises da dinâmica da paisagem em diferentes escalas espaciais e temporais, além de diversas outras informações que podem ser retiradas das imagens de satélite para inúmeros objetivos diferentes (ANDRADE et al., 2014). Neste contexto, o estudo da interação da energia eletromagnética com a água, permite detectar e monitorar a variação espaço-temporal da umidade na paisagem. Existem métodos que utilizam duas ou mais bandas espectrais de imagens de satélites, que são fundamentados no índice espectral da água através das diferenças de reflectância de cada banda para extrair informações da umidade na paisagem, com base no estudo das diferenças de comportamento espectral entre a água e os demais elementos (XU, 2006).

Uma metodologia que vem sendo amplamente utilizada em diversos países, são os índices de umidade para monitorar a cobertura vegetal, estresse hídrico e dinâmica da umidade na paisagem via sensoriamento remoto. Segundo Andrade et al., (2014), esses índices realçam o comportamento espectral da vegetação, da umidade da vegetação e corpos d'água, associadas aos parâmetros biofísicos da cobertura vegetal, tais como biomassa e o índice de área foliar levando em consideração a sua dinâmica fisiológica, fenológica e a identificação de mudanças naturais e/ou antrópicas. Neste sentido, destacam-se o Modified 
XVII Simpósio Brasileiro

de Geografia Fisica Aplicada

I Congresso Nacional de Geografia Física
OS DESAFIOS DA GEOGRAFIA FÍSICA NA FRONTEIRA DO CONHECIMENTO

Instituto de Geociências - Unicamp

Campinas - SP

28 de Junho à 02 de Julho de 2017

Normalized Difference Water Index (MNDWI) (XU, 2006) e o Tasseled Cap Wetness (TCW) (BAIG et al., 2014) dentre os índices mais difundidos com essas características.

Neste sentido, Durán et al., (2010), compararam as diferenças técnicas entre o MDWI e o TCW, concluindo que a transformação TCW apresentou um melhor desempenho e maior consistência para delimitação e discriminação das áreas com maior presença de umidade, tanto para imagens em estação de verão quanto para imagens em estação de inverno. Essa transformação gera uma nova imagem através da combinação linear de seis bandas no qual são delimitados novos eixos diretamente relacionadas as características físicas da imagem (DIAS et al., 2013). Crist \& Cicone (1984) e Gleriani et al., (2003), afirmam que o TCW corresponde ao conteúdo de umidade da vegetação e do solo, sendo relacionado diretamente à banda do infravermelho médio, devido ao contraste entre esta mesma banda e as demais bandas (do azul visível ao infravermelho próximo).

Neste contexto, o presente trabalho visa comparar o IT e o TCW na estimativa da umidade do solo na bacia hidrográfica do rio Corredeiras. A bacia hidrográfica do rio Corredeiras (Figura 1) possui uma área total de $117 \mathrm{~km}^{2}$ e localiza-se no município de Rio Negrinho, região norte do estado de Santa Catarina e apresenta cobertura vegetal de pastagem, reflorestamento de pinus, mata nativa (Floresta Ombrófila Mista), áreas de campo e outros usos em menor proporção.

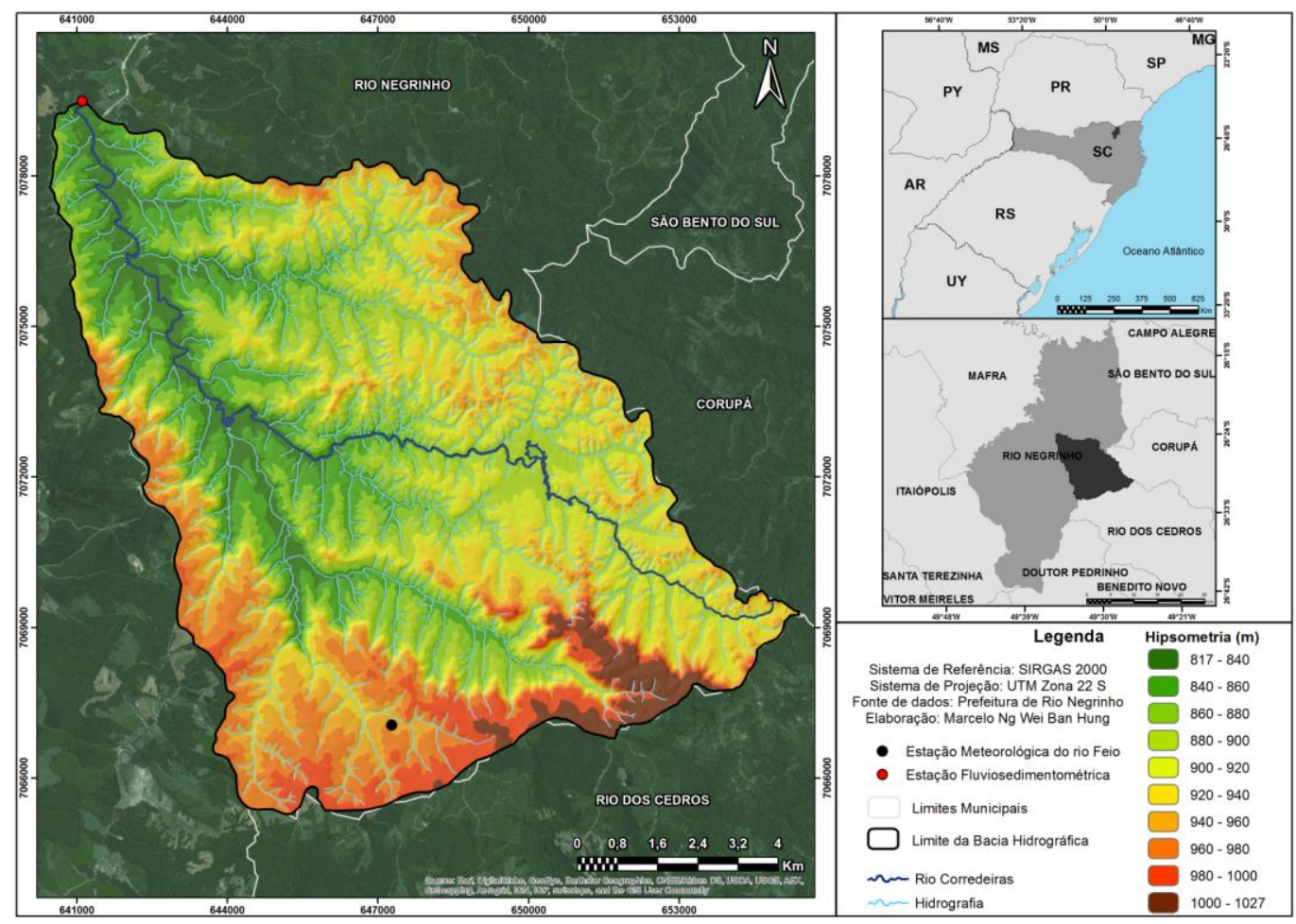

Figura 1 - Localização da bacia hidrográfica do rio Corredeiras. 


\section{Materiais e Métodos}

Para gerar o IT, inicialmente de fez necessário a geração do modelo digital do terreno (MDT), sendo que o mesmo utilizou dados em escala 1:25.000, correspondendo aos pontos cotados, curvas de nível e hidrografia. O algoritmo utilizado para geração do MDT foi o ANUDEM, implementado no ArcMap 9.3 como Topo to Raster. Este algoritmo consiste em um método de interpolação planejado especialmente para a criação de MDTs hidrologicamente consistentes, isto é, são criados modelos digitais do relevo que possuem uma rede de drenagem estruturada e conectada, além de representar de forma mais fidedigna as vertentes e os canais de drenagem (HUTCHINSON, 1989).

A resolução do pixel adotada na geração do MDT foi de $10 \mathrm{~m}$, aplicando como critério a escala de 1:25.000 da base cartográfica que possui curvas de nível com o mesmo valor de $10 \mathrm{~m}$, e deste modo, foi possível utilizar a modelagem do relevo da forma mais detalhada possível levando em consideração a qualidade dos dados topográficos disponíveis para a área de estudo. A partir do MDT, foi gerado o IT no software SAGA GIS 2.1.2 utilizando a ferramenta SAGA Wetness Index. Conforme Böhner \& Selige (2006), este índice é calculado pela seguinte equação:

$$
\mathrm{IT}=\ln \left(\frac{A c m}{\tan \beta}\right)
$$

Onde $A \mathrm{~cm}$ corresponde à área de contribuição modificada e $\tan \beta$ a declividade, sendo que Acm é determinado pela equação 02 :

$$
A c m=\operatorname{Acmax}\left(\frac{1}{15}\right)^{\beta \exp \left(15^{\beta}\right)}
$$

Onde Acmax é a área de contribuição máxima. Nesta equação é utilizado uma constante que determina o limite de tamanho máximo para a grandeza área de contribuição, ou seja, para cada valor de declividade é determinado uma área de contribuição máxima. Deste modo, valores maiores que esses limites são homogeneizados, principalmente em áreas de fundo de vale cujo o objetivo é minimizar a existência de valores aleatórios e fora do padrão em áreas mais planas (BÖHNER \& SELIGE, 2006).

Por outro lado, para a obtenção do índice TCW, foram utilizadas imagens de satélite do LANDSAT 8 para os dias 29/10/14, 29/08/15, 20/01/16 e 30/04/16, de órbita/ponto: 220/78, adquiridas no site Earth Explorer, no qual as imagens já são georreferenciadas e tratadas. As bandas espectrais utilizadas para confeccionar o TCW e seus respectivos comprimentos de ondas são apresentados na tabela 1.

A utilização do TCW através do sensoriamento remoto, primeiramente necessita da conversão dos valores de níveis de cinza para radiância espectral e posterior a transformação em valores de 
reflectância espectral (LI et al., 2013). Conforme USGS (2015), a transformação de níveis de cinza para radiância é feita pela equação 03:

$$
L \lambda=M_{L} * Q c a l+A_{L}
$$

Onde $L \lambda$ é a radiância espectral registada no sensor, $M_{L}$ é o fator de escala multiplicativo para a banda, Qcal são os níveis de cinza e $A_{L}$ é o fator de escala aditivo para a banda. Já a conversão de radiância para reflectância, segundo USGS (2015), é calculado pela equação 04:

$$
\rho \lambda^{\prime}=M_{\rho} * Q \mathrm{cal}+A_{\rho}
$$

Onde $\rho \lambda^{\prime \prime}$ é a reflectância espectral planetária do topo da atmosfera, $M_{\rho}$ é o fator de escala multiplicativo para a banda, $Q c a l$ são os valores de radiância e $A_{\rho}$ é o fator de escala aditivo para a banda. A partir disso, Baig et al., (2014), descrevem o cálculo do TCW a partir da equação 05:

$$
\mathrm{TCW}=\left(c_{2} * B 2\right)+\left(c_{3}^{*} B 3\right)+\left(C_{4} * B 4\right)+\left(c_{5}^{*} B 5\right)+\left(c_{6}^{*} B 6\right)+\left(c_{7} * B 7\right)
$$

Onde $c$ é o coeficiente determinado por Baig et al., (2014) (Tabela 1), para as bandas desde o azul visível até o infravermelho médio (6 bandas) e $B$ corresponde às reflectâncias das mesmas bandas. De acordo com Durán et al., (2013), o TCW possui um bom desempenho e maior consistência na delimitação e discriminação das áreas com maior presença de umidade. Essa transformação gera uma nova imagem através da combinação linear de seis bandas no qual são delimitados novos eixos diretamente relacionadas as características físicas da imagem e demonstra o conteúdo de umidade presente na vegetação e no solo, podendo ser utilizada para a delimitação de áreas propensas a inundação (DIAS et al., 2013).

Tabela 1 - Coeficientes do TCW para as bandas do Landsat 8. Fonte: Baig et al., (2014).

\begin{tabular}{c|c}
\hline Bandas & Coeficientes (c) \\
\hline B2 - Azul & 0,1511 \\
\hline B3 - Verde & 0,1973 \\
\hline B4 - Vermelho & 0,3283 \\
\hline B5 - Infravermelho Próximo (NIR) & 0,3407 \\
\hline B6 - Infravermelho Médio (SWIR 1) & $-0,7117$ \\
\hline B7 - Infravermelho Médio (SWIR 2) & $-0,4559$ \\
\hline
\end{tabular}

\section{Resultados e Discussões}


O IT da bacia hidrográfica do rio Corredeiras (Figura 2) variou de 1 a 11. Observa-se que os valores mais baixos próximos de 1 do índice correspondem às áreas em que, do ponto de vista geomorfológico, estão em posições do relevo menos propicias à saturação hídrica, localizando-se nos terços superiores das vertentes, pois possuem declividade elevada e reduzidas áreas de contribuição a montante. Portanto, são áreas onde o teor de água do solo tende a ser relativamente menor.

Em contrapartida, os maiores valores do IT próximos de 11 situam-se em posições do relevo onde a área de contribuição é elevada e a declividade é baixa, sendo que essa posição topográfica na vertente propicia uma maior probabilidade de saturação hídrica periódica ou permanente do solo. Deste modo, são regiões onde a água escoada da encosta a montante é armazenada, e dessa forma, elevando o nível freático raso (RENNÓ e SOARES, 2003). Portanto, são áreas onde o teor de água do solo é alto. Essas áreas estão associadas com os canais de drenagem e os rios perenes sendo que em um evento de precipitação, são as primeiras áreas à atingirem o estado de saturação hídrica do solo e expandem-se para os valores menores mais próximos, a medida em que a precipitação se prolonga (FREER et al., 2002).

A validação da estimativa do IT foi feita através da verificação em campo como demonstra a Figura 2. O ponto 01 refere-se ao exutório e representa a planície fluvial da bacia do rio Corredeiras. Os pontos 02 a 05 localizam-se em uma vertente no sul da bacia no qual é monitorada pelo Laboratório de Hidrogeomorfologia (LHG) - UFPR, com poços de medição do nível freático. Nestes pontos, nota-se que à medida em que se desloca do terço inferior da vertente em direção ao fundo de vale (do ponto 05 em direção ao ponto 02), o nível freático localiza-se mais próximo da superfície até a ocorrência de áreas de banhado (ponto 02), onde o perfil do solo encontra-se permanentemente saturado.

Os pontos 06 e 08 situam-se na planície do rio Saci e do rio Feio respectivamente. Essas áreas são preferencialmente planas, com grandes áreas de contribuição de escoamento e comprimentos de rampa a montante e baixa declividade. Por fim, o ponto 07 localiza-se no topo da vertente onde não ocorre a saturação hídrica do solo, uma vez que a área de contribuição é pequena. Nestes locais a tendência é de que a água se desloque em direção às regiões mais baixas como os pontos anteriores. No geral, a distribuição espacial dos valores de IT na bacia do rio Corredeiras apresentou resultados condizentes com a realidade. 


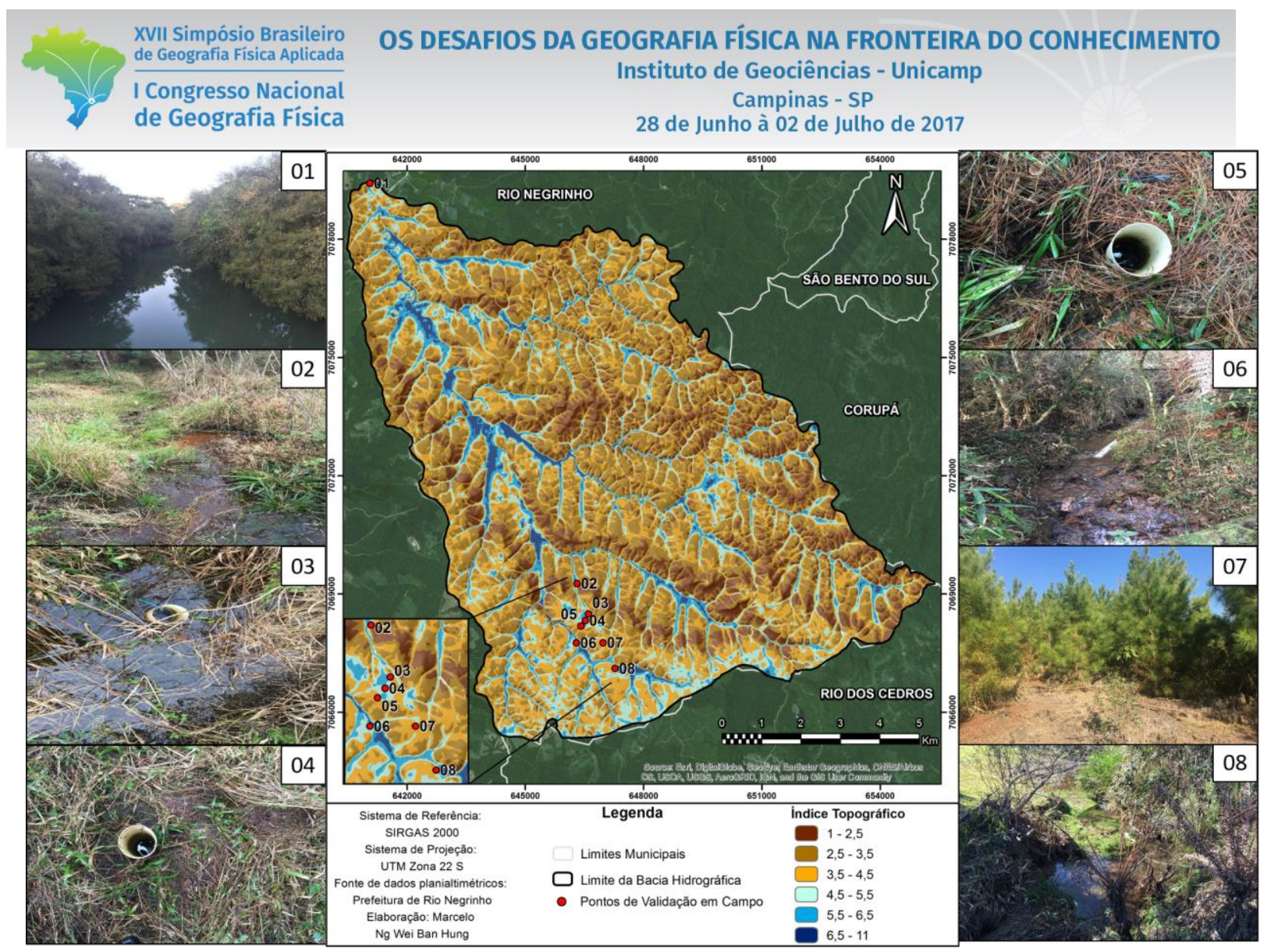

Figura 2 - Índice Topográfico da bacia hidrográfica do rio Corredeiras.

Por outro lado, a Figura 3 apresenta a espacialização do TCW para as quatro imagens selecionadas. As áreas mais próximas ao tom azul são áreas onde a umidade é alta, enquanto que as regiões mais próximas do marrom representam áreas com menor umidade. Entretanto, ao comparar os resultados do TCW com o uso da terra da área de estudo (Figura 4), observa-se que este índice representou as áreas com maior densidade de cobertura vegetal como os locais com maior teor de umidade, ao invés de representar as áreas com solo saturado como as planícies fluviais e banhados. A partir disso, nota-se uma limitação deste índice em relação a área de estudo que possui uma vegetação extremamente densa, onde o clima úmido não representa uma limitação importante para o desenvolvimento da vegetação. Ou seja, nas condições da área de estudo o TCW capta melhor a distribuição espacial da umidade presente na vegetação, em detrimento da umidade do solo. 


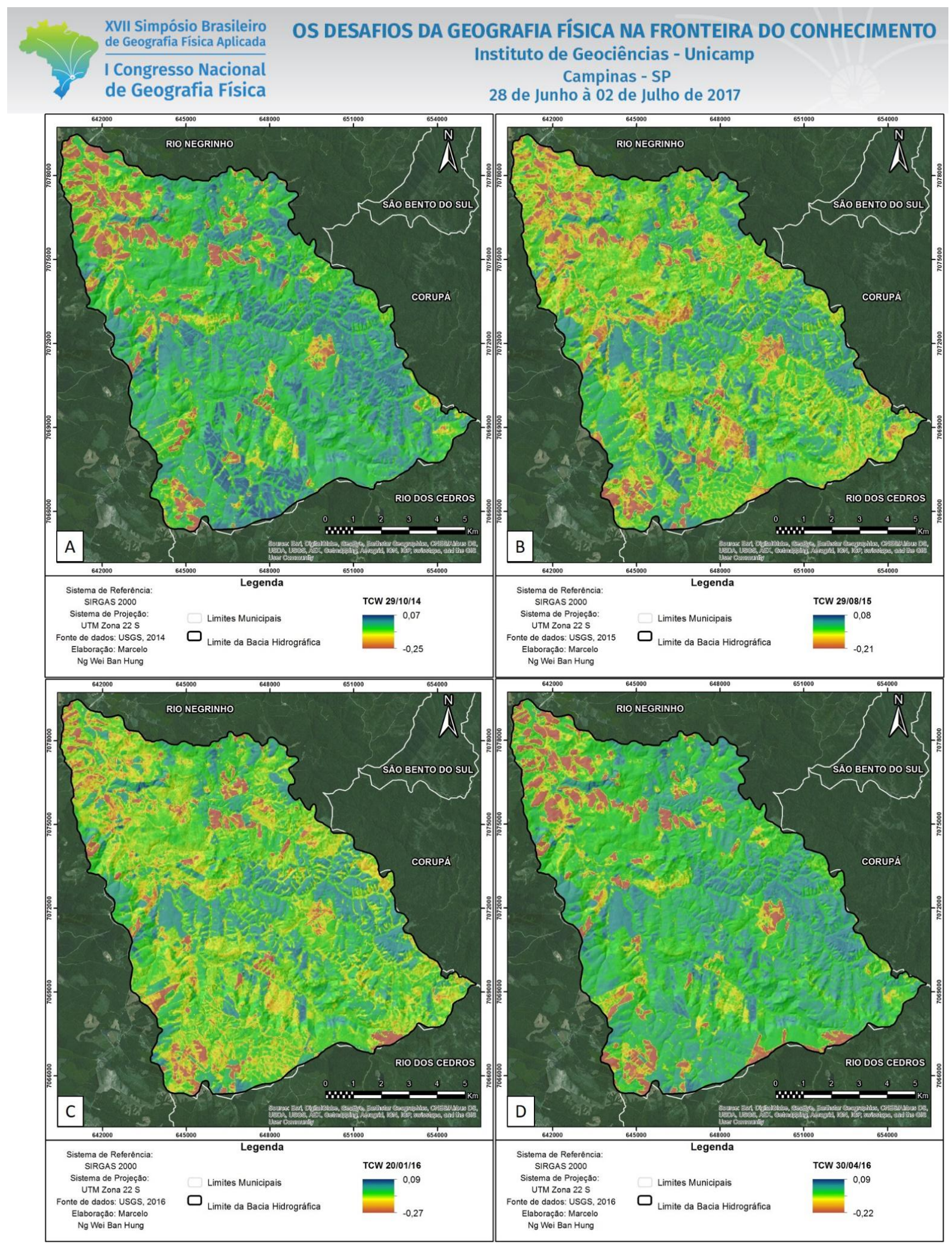

Figura 3 - TCW da bacia do rio Corredeiras para 29/10/14 (A), 29/08/15 (B), 20/01/16 (C) e 30/04/16 (D). 


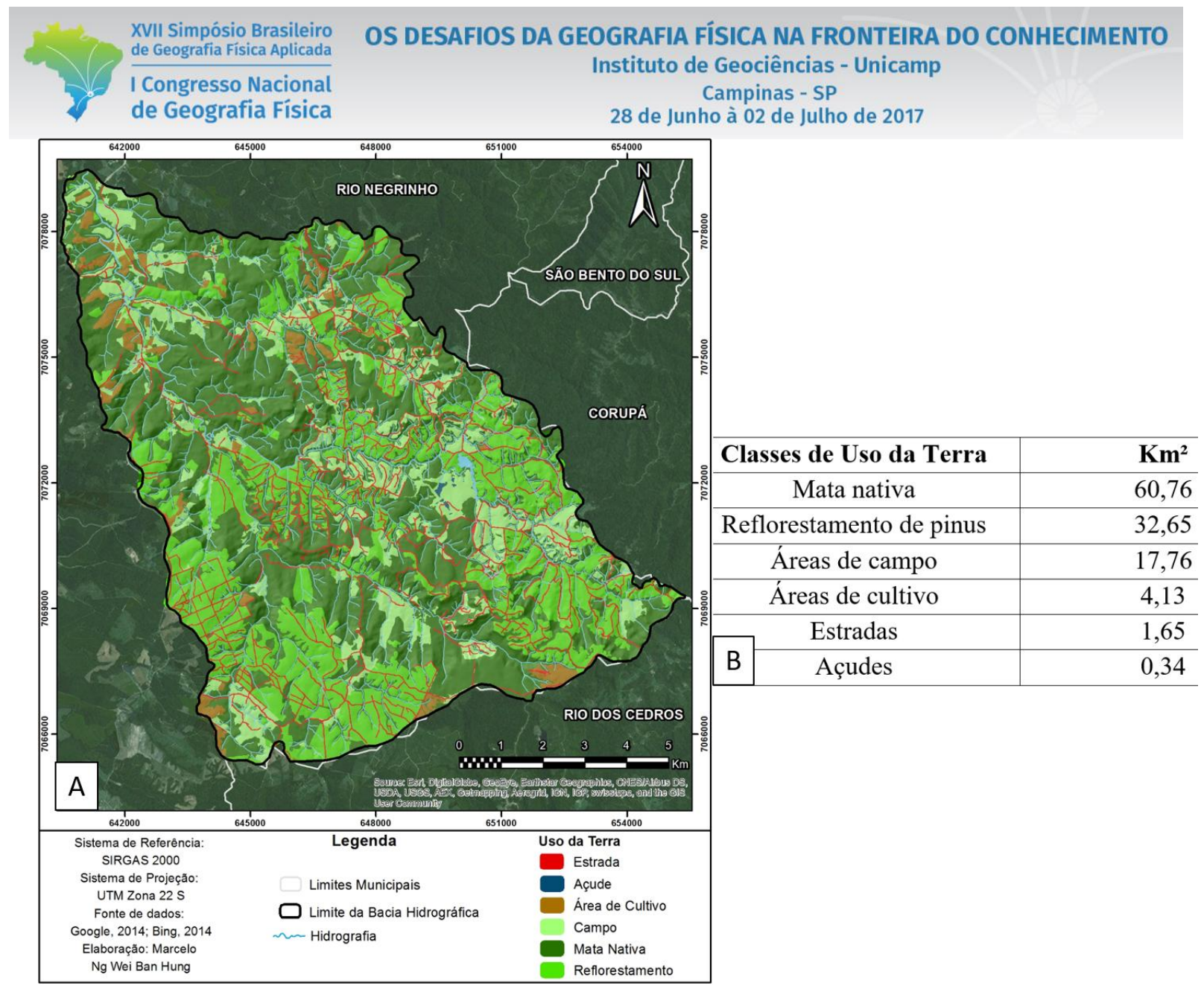

Figura 4 - Uso da terra da bacia do rio Corredeiras (A) e suas respectivas áreas (B) para o ano de 2014. Fonte: Hung (2016).

Esta ocorrência pode ser explicada através da Figura 5 que apresenta a reflexão múltipla da radiação eletromagnética entre camadas de folhas. É possível constatar que para cada camada de folha da vegetação, aproximadamente $50 \%$ da radiação eletromagnética incidente é refletida e $50 \%$ é transmitida por meio das folhas. Deste modo, quando uma segunda camada de folha é sobreposta à primeira, dos $50 \%$ de radiação transmitidos, $25 \%$ podem ser refletidos e $25 \%$ podem ser transmitidos por entre as folhas sendo que este número continua diminuindo conforme a adição de mais camadas de folhas (aumento do índice de área foliar).

Portanto, quanto maior a densidade da cobertura vegetal e consequentemente o índice de área foliar, menor será a capacidade do índice TCW de estimar o teor de umidade do solo. Dessa maneira, na região do visível a reflectância tende a diminuir com o aumento das camadas de folhas da vegetação, enquanto que na região do infravermelho próximo, a reflectância tende a aumentar com o acréscimo de camadas (PONZONI et al., 2015). 


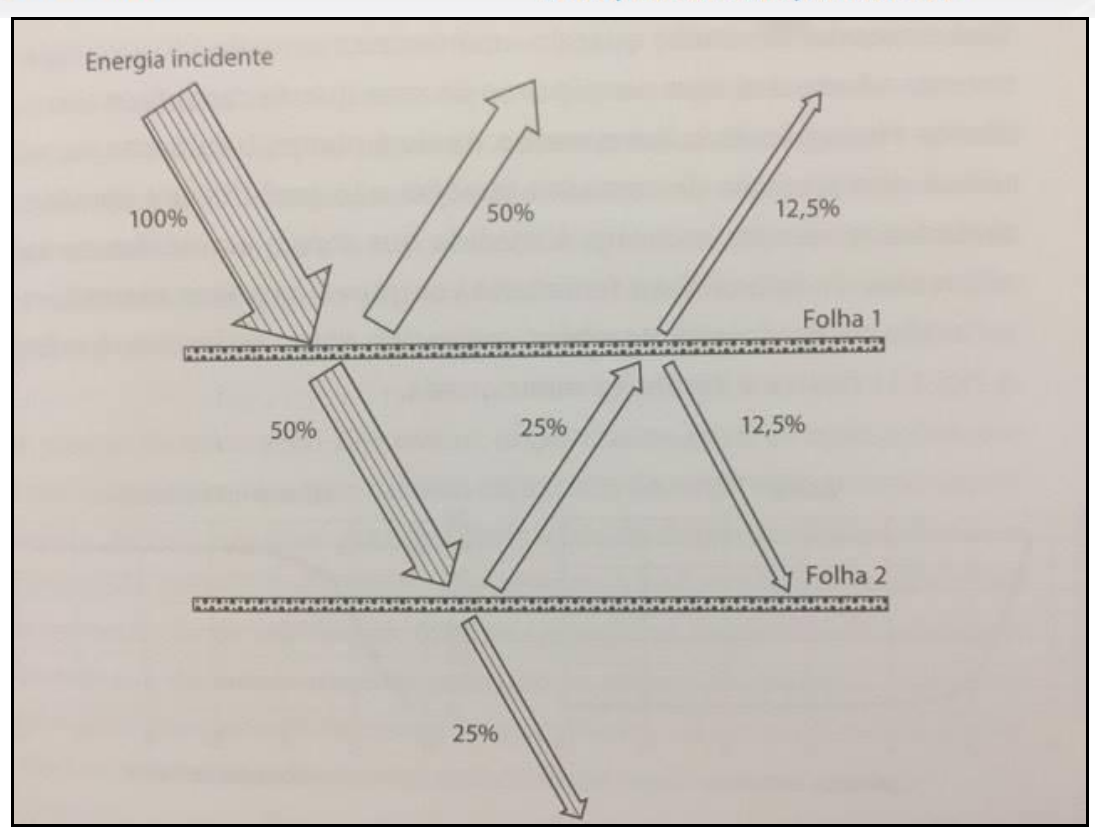

Figura 5 - Exemplo de reflexão múltipla da radiação eletromagnética entre camadas de folhas. Fonte: Ponzoni et al., (2015).

Em regiões de clima mais secos por exemplo, geralmente a vegetação está condicionada a se desenvolver em áreas com maior umidade, ou seja, a vegetação mais desenvolvida normalmente localizase próxima aos canais de drenagem. Porém, para a bacia do rio Corredeiras que se encontra em uma região de clima onde o balanço hídrico resulta sempre positivo, a vegetação não está diretamente relacionada com as áreas de maior umidade do solo. Dentro da área de estudo essas zonas com maior umidade do solo geralmente possuem uma vegetação baixa como as áreas de banhado. O contrário ocorre com a cobertura vegetal mais alta e desenvolvida, que normalmente encontra-se em locais onde o solo possui uma boa drenagem e não ocorre a saturação hídrica. Apesar desta limitação do TCW para indicar a umidade do solo na área de estudo, nota-se que este índice consegue captar a umidade presente na vegetação, a qual também possui uma dinâmica espacial e temporal e variam sazonalmente conforme a precipitação.

\section{Considerações Finais}

O IT se mostrou mais eficiente na estimativa das as áreas que possuem maior probabilidade de saturação hídrica do solo. Deste modo, em comparação com o TCW, conclui-se que o IT representa a distribuição espacial das áreas com maior umidade do solo de forma mais próxima da realidade, principalmente nas porções mais próximas da planície fluvial e da rede de drenagem, chegando a mapear pequenas áreas de banhado permanentes e áreas de saturação temporária ao longo dos canais de drenagem. 
Por outro lado, o TCW apresentou limitações devido a influência da vegetação extremamente densa que impossibilitou o índice em detectar a umidade presente no solo, apresentando em sua grande maioria, áreas com maior cobertura vegetal como as zonas mais úmidas.

\section{Referências}

ANDRADE, S. C. P.; MORAIS, H. F.; DINIZ, J. M. T.; SANTOS, C. A. C. Análise do comportamento do NDVI e NDWI sob diferentes intensidades pluviométricas no município de Sousa - PB. Revista Estudos Geoambientais. Rio Tinto, n. 1, v. 1, 2014.

BAIG, M. H. A.; ZHANG, L.; SHUAI, T.; TONG, Q. Derivation of a tasseled cap transformation based on Landsat 8 at satellite reflectance. Remote Sensing Letters. London - UK, v. 5, n. 5, p. 423-431, 2014.

BÖHNER, J.; SELIGE, T. Spatial prediction of soil atributes using terrain analysis and climate regionalisation. In: Böhner, J., McCloy, K.R., Strobl, J. [Eds.]: Göttinger Geogr. SAGA - Analyses and Modelling Applications. Abh, n. 115, 2006.

BRASIL. Lei Federal $\mathbf{n}^{\mathbf{0}}$ 12.727, de 17 de outubro de 2012. Diário Oficial da República Federativa do Brasil, Brasília, DF, 17 out 2012.

CRIST. E. A TM tasseled cap equivalent transformation for reflectance fator fata. Remote Sensing of Environment, v. 17, p. 301-306, 1984.

DIAS, A. P.; NUNES, G. M.; LENZI, I. L. C.; SILVA, T. S. F. Delimitação de áreas inundadas em período de seca e cheia através da transformação Tasseled Cap e classificador Support Vector Machine em imagens Landsat-5 TM. Anais XVI Simpósio Brasileiro de Sensoriamento Remoto. Foz do Iguaçu - PR, 2013.

DUNNE, T. Field studies of hillslope flow processes. In: M. J. Kirkby (Ed.); Hillslope Hydrology. Chichester: John Wiley \& Sons. p.389, 1978.Durán, G. Y. B.; Sousa_Júnior, M. A. Uso de tecnica Tasseled CAP y de los indices NDWI y MNDWI para la delimitación de áreas propensas a inundación Estado Guárico, Venezuela. In: XIV Simpósio Internacional SELPER, 2010, Guanajuato. Memórias do XIV Simpósio Internacional SELPER. Cidade Mexico: SELPER, 2010. v. 1.

FREER, J.; MCDONNELL, J. J.; BEVEN, K.; PETERS, N.E.; BURNS, D.A., HOOPER, R.P.; AULENBACH, B.; KENDALL, C. The role of bedrock topography on subsurface storm flow. Water Resources Research, v. 38, n. 12, p. 1-19, 2002.

Gleriani, J.M.; Antunes, M.A.H.; Epiphanio, J.C.N. Coeficientes da transformação espectral Tasseled Cap para uma cena com predomínio de latossolo roxo. XI Simpósio Brasileiro de Sensoriamento Remoto. Belo Horizonte, 2003.

HEWLETT, J. D.; HIBBERT, A. R. Factores affecting the response of small watersheds to precipitation in humid areas. (W. E. Sopper, H. W. Lull, Eds.)International Symposium on Forest Hydrology. Anais...Oxford, UK: Pergamon, 1967

HUNG, M. N. W. B. Dinâmica espacial da umidade no solo e na vegetação por meio de modelagem hidrogeomorfológica e sensoriamento remoto na bacia hidrográfica do rio Corredeiras - SC. $99 \mathrm{f}$. Trabalho de conclusão de curso (Bacharelado em Geografia) - Setor de Ciências da Terra, Universidade Federal do Paraná, Curitiba, 2016.

HUTCHINSON, M. F. A new procedure for gridding elevation and stream line data with automatic removal of spurious pits. Journal of Hydrology, v.106, 1989. p. 211-232.

LI, W.; DU, Z.; LING, F.; ZHOU, D.; WANG, H.; GUI, Y.; SUN, B.; ZHANG, X. A comparison of land surface water mapping using the Normalized Difference Water Index from TM, ETM+ and ALI. Remote Sensing. 2013, 5, p. $5530-5549$. 
LOPES, F. C. A. Uso de atributo topográfico para estabelecer relação topografia-vazão na bacia do Altíssimo rio Negro, PR/SC. Revista Geonorte, edição especial, v.3, n.4, p. 1320-1331, 2012.

PARANÁ. Resolução Conjunta IBAMA/SEMA/IAP Nº 005, de 28 de março de 2008. Casa Civil Governadoria do Poder Executivo do Estado do Paraná. Curitiba, PR, 2008.

PONZONI, F. J.; SHIMABUKURO, Y. E.; KUPLICH, T. M. Sensoriamento remoto da vegetação. $2^{\mathrm{a}}$ edição atualizada e ampliada, São Paulo, Oficina de Textos, 2015.

RENNÓ, C. D.; SOARES, J. V. Uso do índice topográfico como estimador da profundidade do lençol freático. Anais XI Simpósio Brasileiro de Sensoriamento Remoto. Anais...Belo Horizonte: Instituto Nacional de Pesquisas Espaciais (INPE), 2003Disponível em: 〈http://marte.dpi.inpe.br/rep-/ltid.inpe.br/sbsr/2002/11.17.22.40>

SILVA, M. M. Dinâmica espaço-temporal das áreas variáveis de afluência da bacia do córrego do Cavalheiro. 143 f. Dissertação (Mestrado em Ciências) - Escola Superior de Agricultura "Luiz de Queiroz", Universidade de São Paulo, Piracicaba, 2012.

USGS - UNITED STATES GEOLOGICAL SURVEY. Landsat 8 (L8) data users handbook. Department of the interior U. S. Geological Survey, v. 1, 2015.

$\mathrm{XU}, \mathrm{H}$. Modification of normalized difference water index (NDWI) to enhance open water features in remotely sensed imagery. Int. J. Remote Sens., 27, 2006, p. 3025-3033. 